\title{
Prevalence of Occlusal Features and Their Relation to Sociodemographic Variables in Northwest Ethiopia: A Cross-Sectional Study
}

\author{
Amare Teshome Tefera (D) \\ Biruk Girma Bekele \\ Kirubel Derese \\ Getaneh Andualem (D)
}

Department of Dentistry, University of Gondar, Gondar, Ethiopia
Correspondence: Kirubel Derese Department of Dentistry, University of Gondar, Gondar, Ethiopia

Tel +25I-9I3866870

Email kirubeld6@gmail.com
Background: Malocclusion affects the chewing, dental aesthetics, jaw development, and overall attractiveness of individuals. The negative impact of malocclusion is high, particularly in adolescents who can be the target of teasing, intimidation, and name-calling. Even if, malocclusion is a common problem in developing countries, there was a paucity of data in Ethiopia. Therefore, this study aimed to determine the prevalence and associated factors of malocclusion in northwest Ethiopia.

Methods: This cross-sectional study was done at the University of Gondar comprehensive hospital from December 1, 2019, to October 30, 2020. Four hundred seventy-six study participants were selected using a systematic random sampling method. Data collection was done using a structured interviewer-administered questionnaire. Qualified dental professionals examined malocclusion traits according to the WHO oral health survey tool and evaluated for the presence of malocclusion in terms of angles classification, open bite, crossbite, spacing, and crowding. Data entry was done using Epi-Info 7, and analyzed by SPSS 26. Descriptive statistics and logistic regression was done to analyze the data.

Results: A total of 476 subjects were included in the study with a mean age of 29.83 (SD \pm 14.013 ). The prevalence of malocclusion was $55.9 \%$ (95\% CI: 51.39-60.28). The common occlusal traits were class-I malocclusion with minor discrepancy (34.9\%), anterior crowding $(22.9 \%)$, and anterior open bite $(21.6 \%)$. The prevalence of anterior crossbite, posterior crossbite, class-II, and class-III malocclusion was $5.9 \%, 3.8 \%, 10.9 \%$, and $8.0 \%$, respectively. Males $(\mathrm{AOR}=1.6,95 \% \mathrm{CI}: 1.11,2.30)$, urban residents $(\mathrm{AOR}=1.64,95 \% \mathrm{CI}: 1.06$, 2.56), monthly income of $\leq 2500$ Ethiopian Birr (AOR=1.27, 95\% CI: 1.02, 1.59) and mouth breathers $(\mathrm{AOR}=2.50,95 \% \mathrm{CI}: 1.72,2.63)$ were significantly associated with malocclusion. Conclusion: Significant amount of the study participants had malocclusion. Males, urban residents, low monthly income, and mouth breathing habits were independent factors for a malocclusion. Therefore, early attention to the development of the dentition and occlusion, and necessary functional correction during childhood are important to reduce its prevalence and lifelong adverse effect. Moreover, publicly financed orthodontic treatment should be scheduled, and supplied to individuals in desperate need of orthodontic care.

Keywords: malocclusion, dentofacial deformity, angles malocclusion, crossbite, open bite

\section{Background}

Malocclusion is defined as an irregularity of the teeth or a mal-relationship between the dental arches beyond the normal range. It is one of the common problems in the oral cavity along with caries and periodontal disease. ${ }^{1}$ Malocclusion affects chewing, speech, articulation, dental aesthetics, jaw development, and overall 
attractiveness, ${ }^{2-7}$ and adults become the target of teasing, intimidation, and name-calling. ${ }^{8}$

Malocclusion is considered a multifactorial condition, which is linked to genetic and environmental factors. ${ }^{9,10}$ Oral habit is one of the environmental factors that affect the occlusal relation of the jaw. ${ }^{11,12}$ Non-nutritive sucking habits that last longer than 3 years are linked to the development of anterior open bite. ${ }^{13}$ A cross-sectional study in China showed that malocclusion had a statistically significant association with residency $(\mathrm{OR}=1.741: 95 \% \mathrm{CI}: 1.384-2.162)$, dental caries $(\mathrm{OR}=2.045 ; 95 \% \mathrm{CI}: 1.665-2.539)$, tongue thrusting $(\mathrm{OR}=2.833$; 95\% CI: 1.640-3.649), and finger sucking (OR $=1.573,95 \% \mathrm{CI}: 1.098-2.014) .{ }^{14}$ Previous literature showed the etiological role of genetic factors in malocclusion has been reduced, bearing in mind that most malocclusions recognize a post-natal origin, related to non-nutritive or nutritive sucking habits at early stages of life and trauma. $^{15-19}$

In Africa, the prevalence of class-I malocclusion was $89 \%{ }^{20}$ The prevalence of malocclusion was $24.7 \%$ in Malaysia, $^{21}$ and $23.7 \%$ in Ethiopia. ${ }^{22}$ An institutionbased cross-sectional study in children in Southwest Ethiopia found a high prevalence of Overjet (30.8\%) and Crowding (23.3\%). ${ }^{23}$ A study done in brazil found a high prevalence of anterior open bite $(21.0 \%)$ and posterior crossbite $(11.6 \%),{ }^{24}$ while Zhou et al in China reported a high prevalence of overjet (34.99\%), deep overbite $(37.58 \%)$, and midline deviation $(25.32 \%)$ in adults. ${ }^{14}$

The self-respect and self-confidence of adults and children were largely dependent on their physical and facial appearance. $^{25-27}$ However, the presence of misaligned teeth embarrass individuals' social interaction and deliberately affect their dental appearance., ${ }^{9,10}$ Moreover, Malocclusion causes psychological problems, functional difficulties, low quality of life, and halitosis, which results from open-mouth breathing habits. ${ }^{26,28}$ A previous study revealed that determining the occlusal features at early permanent dentition would have a significant role in modifying the preventive and interceptive treatment plans. ${ }^{29,30}$

Assessing the prevalence of malocclusion in children and adults may reduce or eliminate future treatment needs, reduce the treatment cost, and plan preventive and curative measures. ${ }^{31}$ Moreover, it is also important for resource planning and funding. ${ }^{32,33}$ This study also will aid in comprehending the required assets and preventive measures and in planning oral health care programs. To date, there is no documented evidence on the prevalence of malocclusion in Northwest Ethiopia. Therefore, this study aimed to assess the prevalence of occlusal features and their relation to sociodemographic variables in Northwest Ethiopia.

\section{Methods Study Design}

A hospital-based cross-sectional study design was employed.

\section{Study Area and Period}

This study was conducted in the University of Gondar compressive hospital, northwest Ethiopia, from December 1, 2019 , to October 30, 2020. This hospital is one of the tertiary hospitals in the country, which is serving about 7 million populations in the catchment area. The dental clinic is one of the specialty centers in the University of Gondar comprehensive hospital that has both outpatient departments and inpatient services. All above 12 years old patients who visited the dental clinic within the study period were candidates for the study. All the study participants were selected using a systematic random sampling method.

\section{Populations}

All patients who visited the University of Gondar comprehensive specialized hospital were the source population, whereas those who visited the dental clinic during the data collection period were the study populations.

\section{Inclusion and Exclusion Criteria}

Study participants that met the following inclusion criteria were included in the study;

- Age of 12 and above years

- Participants who had no previous orthodontic treatment

- A patient who sign the consent form

\section{Exclusion Criteria}

- A patient with developmental anomalies (eg Cleft lip and palate, Down syndrome)

- Permanent dentition present with remaining deciduous teeth

- All participants with missed $1^{\text {st }}$ permanent molar

\section{Sample Size Determination and Sampling Procedures}

The sample size was calculated by using the single population proportion formula by assuming; a prevalence of 
$23.7 \%,{ }^{22} 95 \%$ confidence interval of $\mathrm{Z} \alpha / 2=1.96$, a margin of error $(d)=4$, and a $10 \%$ non-response rate. By considering this, the final sample size became 476 .

A systematic random sampling method was employed to select the study subjects. The sampling interval (K) was calculated by dividing the predicted number of participants per month by the sample size. A lottery method was used to determine the first study participant and every third patient was included in the study $(\mathrm{K}=3)$ until the desired sample size was achieved.

\section{Study Variables}

Dependent Variable: The outcome variable to be investigated was malocclusion.

Independent Variables: The independent variables include; socio-demographic Characteristics (gender, age, marital status, educational status, occupation, religion, residency, and monthly income), history of exclusive breastfeeding, bottle-feeding, and thumb sucking habit.

\section{Data Collection Tools and Quality Assurance}

Data were collected using a structured and intervieweradministered questionnaire. Qualified dentists evaluated the presence of malocclusion using the WHO oral health survey tool. The data collectors to collect the sociodemographic characteristics (age, sex, age, marital status, educational level, occupation, residency, and monthly income) used a structured questionnaire.

A comprehensive orthodontic examination was done for each study participant by one examiner. The basic Angles classification was used to categorize patients' malocclusion traits, ${ }^{34}$ and each participant was classified into one of the following categories: Class-I (normal occlusion, mild deviation from the ideal occlusion and does not compromise aesthetics of function), class II malocclusion, and class III malocclusion. For extra-oral (skeletal malocclusion); patients were seated in normal position and the following parameters were recorded: Facial profile relationship in the anteroposterior dimension, Facial profile convexity, Vertical proportions of the face, and Lips at rest.

To assure the quality of the study, a pretest was done in $10 \%$ of the sample size on participants with similar sociodemographic characteristics. Based on the results, some amendments were done to the prepared tool. A three-day training was given for the data collectors (3 dentists) and two supervisors on the research ethics, objectives of the study, data confidentiality, and consent.

\section{Data Processing and Analysis}

The collected data were entered into Epi-Info (version 7) to clean and code. In $10 \%$ of the collected questionnaires, double-entry was done. Data analysis was done using SPSS software version 26. Frequencies and percentages were calculated and presented using tables and texts. Binary logistic regression was done to explore the association between independent variables and malocclusion. Variables with $\mathrm{P} \leq 0.25$ were entered into the multivariate model to control the possible confounders. Variables independently associated with malocclusion were explored on the bases of adjusted odds ratio (AOR) and 95\% confidence interval.

\section{Ethics Approval and Consent to Participate}

The study was approved by the Institutional Review Board of the University of Gondar and complied with the Declaration of Helsinki Ethical Principles for Medical Research. Written informed consent was taken from each participant before commencing the study. Moreover, written informed consent was obtained from parents or legal guardians for 12-18 years old children. The authors tried to minimize the study participant's confidentiality by avoiding identifiers such as; name and personal ID.

\section{Results \\ Sociodemographic Characteristics of the Study Participants}

A total of 476 study participants with a mean age of 29.83 $(\mathrm{SD} \pm 14.013)$ years with a range of 12 to 85 years were involved in the study. The age range of the study participants was 12 years to 65 years old. More than half $(51.1 \%)$ of the study participants were males. The majority of the study participants were 12-34 years old (73.7\%), married $(46.2 \%)$, orthodox $(89.7 \%)$, urban residents $(78.6 \%)$, and earn $\leq 2500$ Ethiopian Birr monthly (73.7\%) (Table 1).

\section{The Prevalence of Malocclusion Among the Participants}

The prevalence of malocclusion among the study participants was 55.9\% (95\% CI: 51.39-60.28). The commonly occurred malocclusion types in the study participants were; angles Class-I with minor discrepancy (34.9\%), lower anterior crowding (22.9\%), and anterior open bite 
Table I Sociodemographic Characteristics of the Study Participants

\begin{tabular}{|c|c|c|c|}
\hline \multicolumn{2}{|c|}{ Sociodemographic Characteristics } & \multirow{3}{*}{$\begin{array}{l}\quad \text { Frequency (n) } \\
243 \\
233\end{array}$} & \multirow{3}{*}{\begin{tabular}{l}
\multicolumn{2}{r}{ Percentage (\%) } \\
51.1 \\
48.9
\end{tabular}} \\
\hline Gender & Male & & \\
\hline & Female & & \\
\hline \multirow[t]{3}{*}{ Age } & $12-34$ & 351 & 73.7 \\
\hline & $35-49$ & 66 & 13.9 \\
\hline & $\geq 50$ & 59 & 12.4 \\
\hline \multirow[t]{3}{*}{ Marital status } & Single & 220 & 46.2 \\
\hline & Married & 237 & 49.8 \\
\hline & Divorced & 19 & 4.0 \\
\hline \multirow[t]{4}{*}{ Educational status } & Illiterate & 105 & 22.1 \\
\hline & $1-4$ & 70 & 14.7 \\
\hline & $5-8$ & 69 & 14.5 \\
\hline & $9-12$ & 55 & 11.6 \\
\hline \multirow[t]{5}{*}{ Occupation } & Farmer & 71 & 14.9 \\
\hline & Student & 168 & 35.3 \\
\hline & Governmental employee & 86 & 18.1 \\
\hline & Non governmental organization employee & II & 2.3 \\
\hline & Merchant/personal business & 140 & 29.4 \\
\hline \multirow[t]{4}{*}{ Religion } & Orthodox & 427 & 89.7 \\
\hline & Muslim & 30 & 6.3 \\
\hline & Protestant & II & 2.3 \\
\hline & Catholic & 8 & 1.7 \\
\hline \multirow[t]{2}{*}{ Residency } & Urban & 374 & 78.6 \\
\hline & Rural & 102 & 21.4 \\
\hline \multirow[t]{2}{*}{ Monthly income } & $\leq 2500 \mathrm{ETB}$ & 351 & 73.7 \\
\hline & $>2500$ ETB & 125 & 26.3 \\
\hline
\end{tabular}

Abbreviation: ETB, Ethiopian Birr.

(21.6\%). Anterior crossbite $(5.9 \%)$, posterior crossbite (3.8\%), angles class-II malocclusion (10.9\%), and classIII malocclusion (8\%) were relatively low in the study participants (Table 2).

Table 3 presents the distribution of different types of malocclusion based on the socio-demographic characteristic of the study participants.

Males have been affected more by class-I malocclusion with minor discrepancy $(41.6 \%$ vs $28.3 \%)$ and posterior crossbite than females $(9.5 \%$ vs $4.3 \%)$. Adults within the age group of 12-34 years had a high prevalence of anterior cross-bite $(8.3 \%)$, posterior crossbite $(5.7 \%)$ than other age groups. Besides, elders had a high prevalence of angle class-III malocclusion than adults (16.9\%).

Anterior crowding (39.3\%) and anterior crossbite (10.4\%) were relatively high in low socioeconomic status participants ( $\leq 2500$ Ethiopian birr). Rural residents had a higher prevalence of class-I malocclusion with minor discrepancy ( $45.5 \%$ vs $42.2 \%)$, anterior crossbite $(8.8 \%$ vs $5.3 \%)$, class II subdivision 1 ( $13.7 \%$ vs $6.7 \%)$, and class II subdivision 2 malocclusions (9.8\% vs 1.3$)$ than urban residents. However, angle class-III malocclusion ( $7.5 \%$ vs $4.9 \%$ ) was higher in urban residents. Mouth breathers had a high prevalence of angle class-1 malocclusion (31.4\%), anterior crossbite (6.4\%), class-II subdivision 1 (11.8\%), and class-III $(11.5 \%)$ malocclusion than the nasal breathers (Table 3).

Table 4 showed the distribution of different types of malocclusion based on the risk factors (oral habits) of the participants of $12-18$ years.

In participants with a history of exclusive breastfeeding, $67.8 \%$ had no malocclusion and $23.7 \%$ had developed classI malocclusion with a minor discrepancy. Besides, $20.8 \%$ of the study participants with a history of thumb sucking had an anterior open bite and class-II subdivision malocclusion. However, there was no reported class-III and posterior crossbite among 12-18 years adults (Table 4). 
Table 2 Frequency Distribution of the Types of Malocclusion Among the Study Participants

\begin{tabular}{|c|c|c|c|}
\hline \multicolumn{2}{|l|}{ Malocclusion } & \multirow{3}{*}{$\begin{array}{c}\text { Frequency (n) } \\
210 \\
266\end{array}$} & \multirow{3}{*}{$\begin{array}{c}\text { Percentage (\%) } \\
44.1 \\
55.9\end{array}$} \\
\hline Angles class I without minor discrepancy & Yes & & \\
\hline & No & & \\
\hline \multirow[t]{2}{*}{ Angles class-I with minor discrepancy } & Yes & 166 & 34.9 \\
\hline & No & 310 & 65.1 \\
\hline \multirow[t]{2}{*}{ Lower anterior crowding } & Yes & 109 & 22.9 \\
\hline & No & 367 & 77.1 \\
\hline \multirow[t]{2}{*}{ Anterior cross-bite } & Yes & 28 & 5.9 \\
\hline & No & 448 & 94.1 \\
\hline \multirow[t]{2}{*}{ Posterior Cross-bite } & Yes & 18 & 3.8 \\
\hline & No & 458 & 96.2 \\
\hline \multirow[t]{2}{*}{ Anterior open bite } & Yes & 103 & 21.6 \\
\hline & No & 373 & 78.4 \\
\hline \multirow[t]{2}{*}{ Angles class-2 subdivision I malocclusion } & Yes & 40 & 8.4 \\
\hline & No & 436 & 91.6 \\
\hline \multirow[t]{2}{*}{ Angles class- 2 subdivision 2 malocclusion } & Yes & 12 & 2.5 \\
\hline & No & 464 & 97.5 \\
\hline \multirow[t]{2}{*}{ Angles class-3 malocclusion } & Yes & 38 & 8.0 \\
\hline & No & 438 & 92.0 \\
\hline
\end{tabular}

\section{Factors Associated with Malocclusion in the Study Participants}

Bivariate and multivariate logistic regression analysis was done to search for factors associated with malocclusion among the study participants. Males were 1.6 times more likely to develop malocclusion than females with AOR: 1.60; 95\% CI: $1.11-2.30 ; p=0.011$. Urban residents were 1.64 times at risk of developing malocclusion than rural residents $(\mathrm{AOR}=\mathrm{p}=0.026)$. Low socioeconomic status and mouth breathing played a critical role in the morbidity of malocclusion $(\mathrm{P}<0.05)$. There was no significant difference in the prevalence of malocclusion among the different age categories $(\mathrm{p}=0.218)$ (Table 5).

\section{Discussion}

The prevalence of malocclusion in the present study was $55.9 \%$, which corresponds with a study done in Kenya (47\%) (25), Nigeria (42\%), ${ }^{35}$ India (53\%), ${ }^{36}$ Tanzania $(63.8 \%){ }^{25}$ Italy $(59.5 \%)^{9}$ and China $(45.50 \%) .{ }^{37}$ However, this result is low compared with a study done in Kenya (72\%) (29), Rwanda (93\%), ${ }^{38}$ Iran (87\%), ${ }^{39}$ Colombia (88\%), global burden of malocclusion in Africa $(89 \%)^{20}$ and Sudan $(85.3 \%) .{ }^{40}$ Besides, lower results were reported in Brazil (20.0\%) ${ }^{41}$ and Bangladesh
$(24.7 \%) .{ }^{21}$ The difference between our study and others might be due to the ethnicity difference and the use of variable criteria for the classification of the malocclusion.

According to our study class-I malocclusion with a minor discrepancy was found in $34.9 \%$ of our study participants which is similar to a study done in Turkey $(34.9 \%){ }^{42}$ However, this figure is low compared with the global burden of class-I malocclusion in Africa (89.0\%), ${ }^{20}$ and the study done in Libya $(66.5 \%) .{ }^{43}$ The present study also revealed that the prevalence of anterior open bite was $21.6 \%$, which is high compared to a study done in Sudan $(8.5 \%){ }^{44}$ This might be due to the difference in ethnicity and environmental factors among the study participants.

The present study revealed that $22.9 \%$ of the study participants had lower anterior teeth crowding, which is similar to a study done in Nigeria $(21.6 \%) .{ }^{45}$ Moreover, a similar finding (23.3\%) was reported in an epidemiological study done in Southwest Ethiopia. ${ }^{23}$ Nevertheless, other studies done in Nairobi $(47.2 \%)^{46}$ and Rwanda (45$51 \%)^{38}$ have reported higher rates of crowding in the lower jaw. The present study also found that $5.9 \%$ of the study participants had an anterior cross-bite, which is in line with a study done in India (8.48\%), ${ }^{36}$ and Rwanda $(12 \%){ }^{38}$ However, this result is high compared with a study done in Brazil (2.14\%). ${ }^{47}$ Besides, this study 


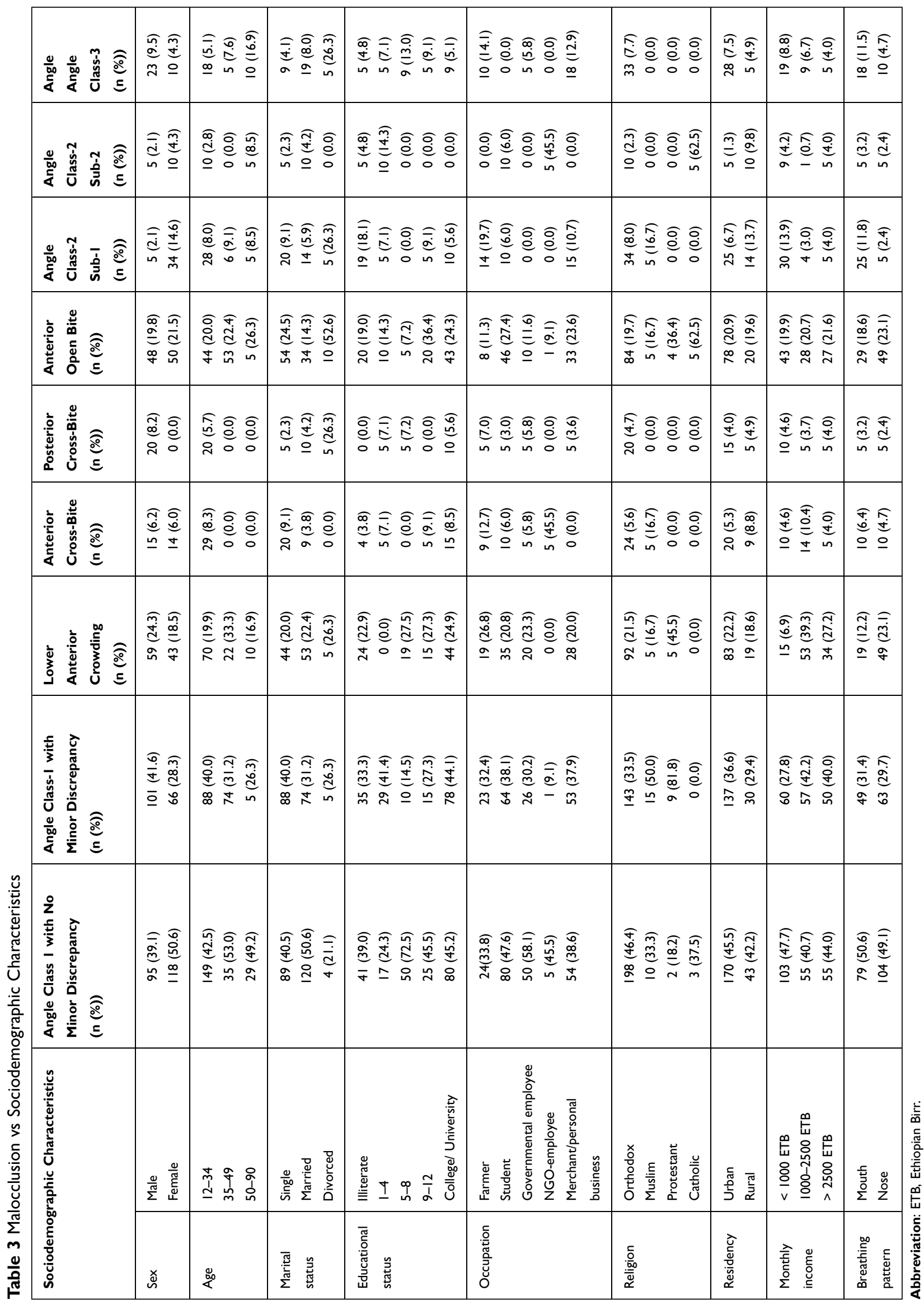




\begin{tabular}{|c|c|c|c|c|}
\hline 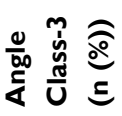 & $\begin{array}{llll}0 & 0 & 0 & 0 \\
\dot{0} & 0 & 0 & 0 \\
0 & 0 & 0 & 0\end{array}$ & $\begin{array}{l}\widehat{\partial} \\
\stackrel{0}{0} \\
0\end{array}$ & $\begin{array}{l}\widehat{0} \\
\stackrel{0}{0}\end{array}$ & $\frac{0}{\stackrel{0}{0}}$ \\
\hline 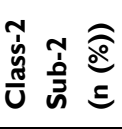 & 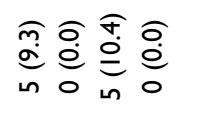 & 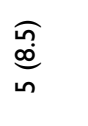 & $\underset{\text { in }}{\stackrel{0}{a}}$ & $\begin{array}{l}\text { ô } \\
\stackrel{d}{d} \\
\text { n }\end{array}$ \\
\hline 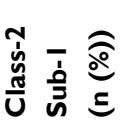 & 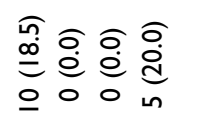 & $\begin{array}{l}\widehat{\partial} \\
\stackrel{\dot{0}}{0}\end{array}$ & $\underset{0}{0}$ & $\underset{0}{\stackrel{0}{e}}$ \\
\hline 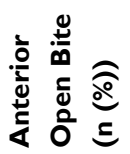 & 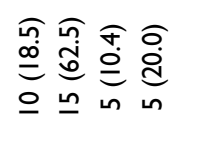 & $\begin{array}{l}\substack{n \\
\infty \\
\infty} \\
\text { in }\end{array}$ & 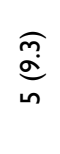 & $\begin{array}{l}\text { ô } \\
\stackrel{d}{d} \\
\text { n }\end{array}$ \\
\hline 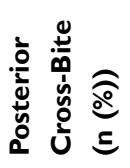 & $\begin{array}{llll}0 & 0 & 0 & 0 \\
0 & 0 & 0 \\
0 & 0 & 0 & 0 \\
0 & 0 & 0 & 0\end{array}$ & $\begin{array}{l}\hat{\circ} \\
\stackrel{0}{0}\end{array}$ & $\underset{0}{\stackrel{0}{0}}$ & 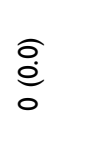 \\
\hline 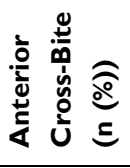 & $\begin{array}{llll}\widehat{a} & 0 & 0 & 0 \\
o & 0 & 0 & 0 \\
\text { in } & 0 & 0 & 0\end{array}$ & $\begin{array}{l}\hat{\circ} \\
\stackrel{\rho}{0} \\
0\end{array}$ & $\begin{array}{l}\hat{O} \\
\stackrel{0}{0} \\
0\end{array}$ & 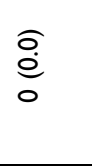 \\
\hline 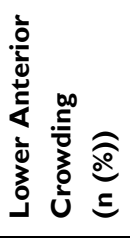 & 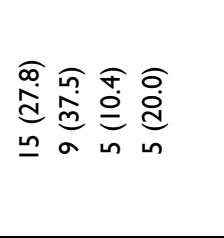 & $\underset{0}{\stackrel{0}{0}}$ & 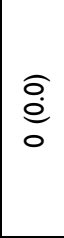 & $\frac{0}{\dot{0}}$ \\
\hline 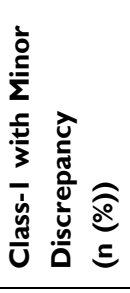 & 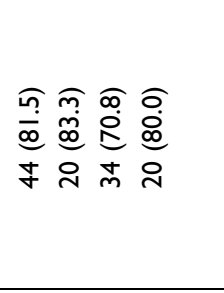 & $\begin{array}{l}\underset{\mathfrak{d}}{\tilde{d}} \\
\underline{\underline{u}}\end{array}$ & $\begin{array}{l}\underset{f}{6} \\
\stackrel{0}{\sigma} \\
\sigma\end{array}$ & $\begin{array}{l}\frac{1}{\stackrel{n}{0}} \\
\stackrel{m}{0} \\
a\end{array}$ \\
\hline 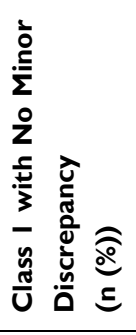 & 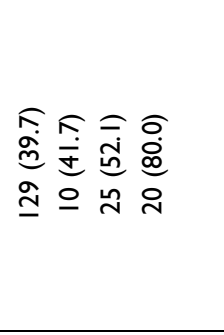 & 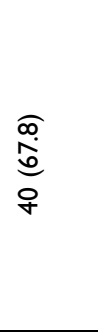 & 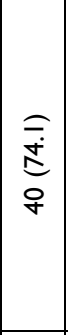 & $\begin{array}{l}\frac{5}{b} \\
\frac{5}{ \pm} \\
\text { O }\end{array}$ \\
\hline & 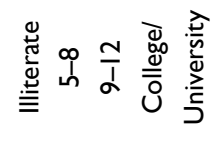 & $\stackrel{\check{\nu}}{\check{\nu}}$ & $\stackrel{\mathscr{y}}{\nu}$ & $\stackrel{\check{\nu}}{\check{\nu}}$ \\
\hline 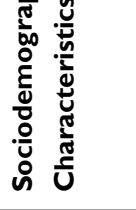 & 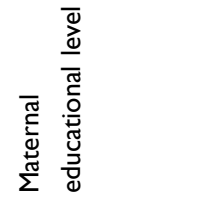 & 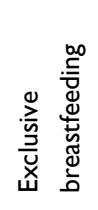 & 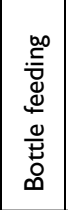 & 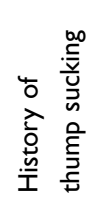 \\
\hline
\end{tabular}

found $21.6 \%$ of the study participants had an anterior open bite. This value corresponds with previous studies done in Tanzania (16.1\%), ${ }^{25}$ and Kenya. ${ }^{46}$

Only $3.8 \%$ of the participants had a posterior crossbite, this result is similar to a study done in Brazil, where $3.1 \%$ of the participants had functional posterior crossbite and $7 \%$ of the pacifier users had posterior cross-bite. ${ }^{48}$ However, this result is low compared with a study done in Turkey $(51.0 \%) .{ }^{49}$ The difference might be due to racial and age differences between the studies.

The prevalence of class-II malocclusion was 10.9 of which, $8.4 \%$ had class -II subdivision 1 , and $2.5 \%$ had class-II subdivision 2 , which is relatively similar to the global prevalence in African populations (5.1\%). ${ }^{20}$ This result is high compared with a study done in Nigeria $(1.7 \%)^{45}$ and Tanzania (4.4\%). ${ }^{25}$ However, a study done in urban Libya showed $21.9 \%$ of the participants had class-II subdivision 1 malocclusion. ${ }^{43}$

The Global distribution of malocclusion traits found that class-III malocclusion was the least prevalent condition in the Africans, which supports the present study where only $8 \%$ of the participants had developed a class-III malocclusion. ${ }^{20}$ Meanwhile, a systematic review done in Iran showed only $5.5 \%$ of the patients in Iran had a class-III relation. ${ }^{39}$ However, a study done in Sudan found $58.7 \%{ }^{40}$ of the study participants had class-III malocclusion. This difference might be the study done in Sudan includes Down syndrome patients who are more prone to jaw development problems.

The present study found that urban residents were 1.64 times at risk of developing malocclusion than rural residents which corresponds with a study done in India where a higher prevalence of class-III malocclusion was reported among urban residents. ${ }^{50}$ However, a systematic review and meta-analysis in china did not find a significant difference in malocclusion between the urban and rural residents $(\mathrm{RR}=0.99,[0.82-1.20]){ }^{37}$

A correlational study done in India revealed that mouth breathing had a statistically significant effect on the occurrence of malocclusion $((\mathrm{AOR}=0.013,95 \% \mathrm{CI}:-6.807$, $-0.787),{ }^{36}$ which supports the present study where mouth breathers were 2.50 times at risk of developing malocclusion. Moreover, a study done in Italy on preschool children found a statistically significant association between mouth breathing and malocclusion $(\mathrm{p}<0.05) .^{51}$

The present study noted that male participants were more likely to suffer from malocclusion, which is similar to a study done in India $^{52}$ where class-II and malocclusion were high in boys. Moreover, Tang and Wei also reported 
Table 5 Binary Logistic Regression Model to Determine the Association Between the Independent Variables and Malocclusion

\begin{tabular}{|c|c|c|c|c|c|}
\hline \multicolumn{2}{|l|}{ Variable } & \multicolumn{2}{|c|}{ Malocclusion } & \multirow[t]{2}{*}{ AOR } & \multirow[t]{2}{*}{ P-value } \\
\hline & & Yes (n) & No (n) & & \\
\hline Sex & $\begin{array}{l}\text { Male } \\
\text { Female }\end{array}$ & $\begin{array}{l}148 \\
115\end{array}$ & $\begin{array}{l}95 \\
118\end{array}$ & $\begin{array}{l}1.6(1.11,2.3) \\
1\end{array}$ & 0.011 \\
\hline Age & $\begin{array}{l}12-34 \\
35-49 \\
\geq 50\end{array}$ & $\begin{array}{c}202 \\
31 \\
30\end{array}$ & $\begin{array}{l}149 \\
35 \\
29\end{array}$ & $\begin{array}{l}\text { I.75 }(0.82,2.99) \\
0.8 \mathrm{I}(0.27,1.63) \\
\mathrm{I}\end{array}$ & 0.218 \\
\hline Marital status & $\begin{array}{l}\text { Single } \\
\text { Married } \\
\text { Divorced }\end{array}$ & $\begin{array}{l}131 \\
117 \\
15\end{array}$ & $\begin{array}{l}89 \\
120 \\
4\end{array}$ & $\begin{array}{l}0.85(0.33,2.72) \\
\text { I.56 (0.6I, } 4.70) \\
\text { I }\end{array}$ & 0.09 \\
\hline Residency & $\begin{array}{l}\text { Urban } \\
\text { Rural }\end{array}$ & $\begin{array}{c}204 \\
59\end{array}$ & $\begin{array}{l}170 \\
43\end{array}$ & $\begin{array}{l}\text { I.6465 (I.0577, 2.5632) } \\
\text { I }\end{array}$ & 0.026 \\
\hline Monthly income & $\begin{array}{l}\leq 2500 \text { ETB } \\
>2500 \text { ETB }\end{array}$ & $\begin{array}{l}193 \\
70\end{array}$ & $\begin{array}{l}158 \\
55\end{array}$ & $\begin{array}{l}\text { I.2728 (I.0192, I.5895) } \\
\text { । }\end{array}$ & 0.023 \\
\hline Breathing pattern & $\begin{array}{l}\text { Mouth } \\
\text { Nose }\end{array}$ & $\begin{array}{l}160 \\
106\end{array}$ & $\begin{array}{l}79 \\
131\end{array}$ & $\begin{array}{l}2.503(1.7259,3.63) \\
\text { । }\end{array}$ & $<0.0001$ \\
\hline
\end{tabular}

Abbreviation: ETB, Ethiopian Birr.

a high prevalence of class-II and III malocclusions than females. ${ }^{34}$ Moreover, participants within low socioeconomic status were 1.27 times at risk of developing malocclusion, which is in line with previous studies. ${ }^{53-55}$ However, a study done in Turkey did not find a statistically significant relationship between socio-economic status and malocclusion. ${ }^{56}$

\section{Limitation and Strength of the Study}

The present study has some limitations. The first limitation was that risk factor was not explored for each different type of malocclusion. Secondly, most of the parents did not recall their child's habit for 12-18 children. Moreover, the findings in this study did not represent the general prevalence of malocclusion in the country due to the small sample size.

This is the first study in the area and gives epidemiologic data of malocclusion in Northwest Ethiopia. In this study, random sampling was used to decrease bias. Moreover, the findings of this study are useful for public health planning and hypothesis creation for future studies.

\section{Conclusion}

A significant amount of the study participants had malocclusion. Male gender, urban resident, low monthly income, and mouth breathing habits were independent factors for a malocclusion. Therefore, early attention to the development of the dentition and occlusion, and necessary functional correction during childhood are important to reduce its prevalence and lifelong adverse effect. Moreover, publicly financed orthodontic treatment should be scheduled and supplied to individuals in desperate need of orthodontic care.

\section{Abbreviations}

CI, confidence interval; IRB, Institutional Review Board; OR, odds ratio; WHO, World Health Organization; SD, standard deviation; SPSS, Statistical Package for the Social Science.

\section{Data Sharing Statement}

All the data obtained were included in the main manuscript.

\section{Ethical Approval and Consent to Participate}

The study was approved by the Institutional Review Board of the University of Gondar and complied with the Declaration of Helsinki Ethical Principles for Medical Research. Written consent was taken after the study participants were briefed for the aim of the study and written informed consent was obtained from parents or legal guardians for 12-18 years old children.

\section{Acknowledgments}

We would like to acknowledge the University of the Gondar IRB for the ethical clearance and all the study 
participants for their involvement in the study. Lastly, the authors extend their thanks to the staff of the department of dentistry for their participation in the data collection process.

\section{Author Contributions}

All authors made a significant contribution to the work reported, whether that is in the conception, study design, execution, acquisition of data, analysis, and interpretation, or in all these areas; took part in drafting, revising, or critically reviewing the article; gave final approval of the version to be published; have agreed on the journal to which the article has been submitted; and agree to be accountable for all aspects of the work.

\section{Funding}

The authors declare there was no external funding for the study.

\section{Disclosure}

The authors declare that they do not have competing interests.

\section{References}

1. Dhar V, Jain A, Van Dyke TE, Kohli A. Prevalence of gingival diseases, malocclusion and fluorosis in school-going children of rural areas in Udaipur district. J Indian Soc Pedod Prev Dent. 2007;25 (2):103. doi:10.4103/0970-4388.33458

2. English JD, Buschang PH, Throckmorton GS. Does malocclusion affect masticatory performance? Angle Orthod. 2002;72(1):21-27.

3. Gupta DK, Singh SP, Utreja A, Verma S. Prevalence of malocclusion and assessment of treatment needs in $\beta$-thalassemia major children. Prog Orthod. 2016;17(1):7. doi:10.1186/s40510-016-0120-6

4. Palomares NB, Celeste RK, de Oliveira BH, Miguel JAM. How does orthodontic treatment affect young adults' oral health-related quality of life? Am J Orthod Dentofacial Orthop. 2012;141(6):751-758. doi:10.1016/j.ajodo.2012.01.015

5. Havens DC, McNamara JA Jr, Sigler LM, Baccetti T. The role of the posed smile in overall facial esthetics. Angle Orthod. 2010;80 (2):322-328. doi:10.2319/040409-194.1

6. Henson ST, Lindauer SJ, Gardner WG, Shroff B, Tufekci E, Best AM. Influence of dental esthetics on social perceptions of adolescents judged by peers. Am J Orthod Dentofacial Orthop. 2011;140 (3):389-395. doi:10.1016/j.ajodo.2010.07.026

7. Shaw WC, Rees G, Dawe M, Charles CR. The influence of dentofacial appearance on the social attractiveness of young adults. Am J Orthod. 1985;87(1):21-26. doi:10.1016/0002-9416(85)90170-8

8. Bernabé E, De Oliveira CM, Sheiham A. Condition-specific sociodental impacts attributed to different anterior occlusal traits in Brazilian adolescents. Eur J Oral Sci. 2007;115(6):473-478. doi:10.1111/j.1600-0722.2007.00486.x

9. Nobile CG, Pavia M, Fortunato L, Angelillo IF. Prevalence and factors related to malocclusion and orthodontic treatment need in children and adolescents in Italy. Eur J Public Health. 2007;17(6):637-641. doi:10.1093/eurpub/ckm016
10. Shivakumar KM, Chandu GN, Reddy VS, Shafiulla MD. Prevalence of malocclusion and orthodontic treatment needs among middle and high school children of Davangere city, India by using Dental Aesthetic Index. J Indian Soc Pedod Prev Dent. 2009;27(4):211. doi:10.4103/0970-4388.57655

11. Klocke A, Nanda R, Kahl-Nieke B. Anterior open bite in the deciduous dentition: longitudinal follow-up and craniofacial growth considerations. Am J Orthod Dento Orthoped. 2002;222:358.

12. Mistry P, Moles DR, O'Neill J, Noar J. The occlusal effects of digit sucking habits amongst school children in Northamptonshire (UK). J Orthod. 2010;37(2):87-92. doi:10.1179/14653121042939

13. Dimberg L, Lennartsson B, Soderfeldt B, et al. Malocclusions in children at 3 and 7 years of age: a longitudinal study. Eur J Orthod. 2013;35(1):131-137. doi:10.1093/ejo/cjr110

14. Zhou Z, Liu F, Shen S, Shang L, Shang L, Wang X. Prevalence of and factors affecting malocclusion in primary dentition among children in Xi'an, China. BMC Oral Health. 2016;16(1):91. doi:10.1186/ s12903-016-0285-x

15. Karjalainen S, Rönning O, Lapinleimu H, Simell O. Association between early weaning, non-nutritive sucking habits and occlusal anomalies in 3-year-old Finnish children. Int $J$ Paediatr Dent. 1999;9(3):169-173. doi:10.1046/j.1365-263x.1999.00133.x

16. Odont EL. Sucking, chewing, and feeding habits and the development of crossbite: a longitudinal study of girls from birth to 3 years of age. Angle Orthod. 2001;71(2):116-119.

17. Shyama M, Al-Mutawa SA, Honkala S. Malocclusions and traumatic injuries in disabled schoolchildren and adolescents in Kuwait. Spec Care Dentist. 2001;21(3):104-108. doi:10.1111/j.1754-4505.2001. tb00235.x

18. Warren JJ, Bishara SE, Steinbock KL, Yonezu T, Nowak AJ. Effects of oral habits' duration on dental characteristics in the primary dentition. $J$ Am Dent Assoc. 2001;132(12):1685-1693. doi:10.14219/jada. archive.2001.0121

19. Warren JJ, Bishara SE. Duration of nutritive and nonnutritive sucking behaviors and their effects on the dental arches in the primary dentition. Am J Orthod Dentofacial Orthop. 2002;121(4):347-356. doi:10.1067/mod.2002.121445

20. Alhammadi MS, Halboub E, Fayed MS, Labib A, El-Saaidi C. Global distribution of malocclusion traits: a systematic review. Dent Press J Orthod. 2018;23(6):40-e1. doi:10.1590/2177-6709.23.6.40. e1-10.onl

21. Sultana S, Hossain Z. Prevalence and factors related to malocclusion, normative and perceived orthodontic treatment need among children and adolescents in Bangladesh. Dent Press J Orthod. 2019;24(3):44e1. doi:10.1590/2177-6709.24.3.44.e1-9.onl

22. Simon C, Tesfaye F, Berhane Y. Assessment of the oral health status of school children in Addis Ababa. Ethiop Med J. 2003;41 (3):245-256.

23. Tolessa M, Singel AT, Merga H. Epidemiology of orthodontic treatment need in southwestern Ethiopian children: a cross sectional study using the index of orthodontic treatment need. BMC Oral Health. 2020;20(1):210. doi:10.1186/s12903-020-01196-2

24. de Sousa RV, Ribeiro GLA, Firmino RT, Martins CC, GranvilleGarcia AF, Paiva SM. Prevalence and associated factors for the development of anterior open bite and posterior crossbite in the primary dentition. Braz Dent J. 2014;25(4):336-342. doi:10.1590/ 0103-6440201300003

25. Mtaya M, Brudvik P, AAstrøm AN. Prevalence of malocclusion and its relationship with socio-demographic factors, dental caries, and oral hygiene in 12-to 14-year-old Tanzanian schoolchildren. Eur J Orthod. 2009;31(5):467-476. doi:10.1093/ejo/cjn125

26. Tausche E, Luck O, Harzer W. Prevalence of malocclusion in the early mixed dentition and orthodontic treatment need. Am J Orthod Dentofacial Orthop. 2005;127(3):394. doi:10.1016/j.ajodo.200 4.11 .002 
27. Aikins EA. Self-perception of malocclusion among Nigerian adolescents using the aesthetic component of the IOTN. Open Dent J. 2012;6:61. doi:10.2174/1874210601206010061

28. Ackerman A, Wiltshire WA. The occlusal status of disabled children. $J$ Dent Assoc South Afr Tydskr Van Tandheelkd Ver Van Suid-Afr. 1994;49(9):447-451.

29. Elfseyie MTM, Abdullah NM, Hassan MIA. Occlusal features of 12 years old Malaysian Malay school-children in Shah Alam. Compend Oral Sci. 2014;1(1):6-12.

30. Elfseyie M, Al-Jaf N, Hassan M. Prevalence and gender differences of buccally displaced canines of 12 years school children and 18-23 years adults in Shah-Alam, Malaysia. Int J Dent Res. 2021;6 (2):39-42. doi:10.31254/dentistry.2021.6204

31. Ngom PI, Diagne F, Aïdara-Tamba AW, Sene A. Relationship between orthodontic anomalies and masticatory function in adults. Am J Orthod Dentofacial Orthop. 2007;131(2):216-222. doi:10.1016/j.ajodo.2005.03.027

32. World Health Organization. Oral Health Surveys: Basic Methods. World Health Organization; 2013.

33. Ackerman JL, Proffit WR. Preventive and interceptive orthodontics: a strong theory proves weak in practice. Angle Orthod. 1980;50 (2):75-86.

34. Tang EL, Wei SH. Recording and measuring malocclusion: a review of the literature. Am J Orthod Dentofacial Orthop. 1993;103 (4):344-351. doi:10.1016/0889-5406(93)70015-G

35. Popoola BO, Onyejaka N, Folayan MO. Prevalence of developmental dental hard-tissue anomalies and association with caries and oral hygiene status of children in Southwestern, Nigeria. BMC Oral Health. 2017;17(1):8. doi:10.1186/s12903-016-0236-6

36. Pruthi N, Sogi GM, Fotedar S. Malocclusion and deleterious oral habits in a north Indian adolescent population: a correlational study. Eur J Gen Dent. 2013;2(3):257. doi:10.4103/2278-9626.116013

37. Shen L, He F, Zhang C, Jiang H, Wang J. Prevalence of malocclusion in primary dentition in mainland China, 1988-2017: a systematic review and meta-analysis. Sci Rep. 2018;8(1):1-10.

38. Goyal S. Prevalence of malocclusion in Rwandan people in a hospital-based study. Rwanda Med J. 2018;75(3):1-8.

39. Eslamipour F, Afshari Z, Najimi A. Prevalence of malocclusion in permanent dentition of Iranian population: a review article. Iran J Public Health. 2018;47(2):178.

40. Ibrahim HA, Abuaffan AH. Prevalence of malocclusion and orthodontic treatment needs among down syndrome Sudanese individuals. Braz Dent Sci. 2015;18(1):95-101. doi:10.14295/bds.2015.v18i1.1076

41. Teixeira AKM, Antunes JLF, Noro LRA. Factors associated with malocclusion in youth in a municipality of Northeastern Brazil. Rev Bras Epidemiol. 2016;19:621-631. doi:10.1590/1980-5497201600030012

42. Bilgic F, Gelgor IE, Celebi AA. Malocclusion prevalence and orthodontic treatment need in central Anatolian adolescents compared to European and other nations' adolescents. Dent Press J Orthod. 2015;20(6):75-81. doi:10.1590/2177-6709.20.6.075-081.oar
43. Bugaighis I, Karanth D. The prevalence of malocclusion in urban Libyan schoolchildren. J Orthod Sci. 2013;2(1):1. doi:10.4103/22780203.110325

44. Hassan D, Abuaffan A. Prevalence of Anterior Open Bite Among Sample of Sudanese University Students. Enz Eng. 2016;5(143):2.

45. Dacosta OO. The prevalence of malocclusion among a population of northern Nigeria school children. West Afr J Med. 1999;18(2):91-96.

46. Muasya MK, Opinya GN, Macigo FG. Malocclusion and orthodontic treatment need among 12-15-year-old children in Nairobi. East Afr Med J. 2012;89(2):39-44.

47. de Lira ADLS, da Fonseca GHA. Anterior crossbite malocclusion: prevalence and treatment with a fixed inclined plane orthodontic appliance. Braz J Oral Sci. 2019;18:e191502-e191502. doi:10.20396/bjos.v18i0.8657251

48. Scavone H, Ferreira RI, Mendes TE, Ferreira FV. Prevalence of posterior crossbite among pacifier users: a study in the deciduous dentition. Braz Oral Res. 2007;21(2):153-158. doi:10.1590/s180683242007000200010

49. Gungor K, Taner L, Kaygisiz E. Prevalence of posterior crossbite for orthodontic treatment timing. J Clin Pediatr Dent. 2016;40 (5):422-424. doi:10.17796/1053-4628-40.5.422

50. Kaur H, Pavithra US, Abraham R. Prevalence of malocclusion among adolescents in South Indian population. J Int Soc Prev Community Dent. 2013;3(2):97. doi:10.4103/2231-0762.122453

51. Paolantonio EG, Ludovici N, Saccomanno S, La Torre G, Grippaudo C. Association between oral habits, mouth breathing and malocclusion in Italian preschoolers. Eur J Paediatr Dent. 2019;20 (3):204-208.

52. Siddegowda R, Satish RM. The prevalence of malocclusion and its gender distribution among Indian school children: an epidemiological survey. SRM J Res Dent Sci. 2014;5(4):224. doi:10.4103/0976433X.145118

53. Rauten AM, Olteanu M, Maglaviceanu C, Popescu MR, Teodorescu E, Surlin P. Malocclusions assessment in a group of Romanian school children with different socio-economic status. Int J Med Dent. 2014;4(3):181-188.

54. Bernabé E, Flores-Mir C. Normative and self-perceived orthodontic treatment need of a Peruvian university population. Head Face Med. 2006;2(1):1-8. doi:10.1186/1746-160X-2-22

55. Doğan AA, Sari E, Uskun E, Şahin Sağlam AM. Comparison of orthodontic treatment need by professionals and parents with different socio-demographic characteristics. Eur J Orthod. 2010;32 (6):672-676. doi:10.1093/ejo/cjp161

56. Oz E, Kucukesmen C. Evaluation of the relationship between malocclusion and the periodontal health, caries, socio-economic status of children [Cocuklarda Gorulen Malokluzyonlar ile Periodontal Saglik, Dis Curukleri ve Sosyo-ekonomik Durum Arasindaki Iliskinin Degerlendirilmesi]. Meandros Med Dent J. 2019;20(1):20-28. doi:10.4274/meandros.galenos.2018.63835
Clinical, Cosmetic and Investigational Dentistry

\section{Publish your work in this journal}

Clinical, Cosmetic and Investigational Dentistry is an international, peer-reviewed, open access, online journal focusing on the latest clinical and experimental research in dentistry with specific emphasis on cosmetic interventions. Innovative developments in dental materials, techniques and devices that improve outcomes and patient satisfaction and preference will be highlighted. The manuscript management system is completely online and includes a very quick and fair peer-review system, which is all easy to use. Visit http://www.dovepress.com/testimonials.php to read real quotes from published authors. 